\title{
Influence of Unilateral Muscle Fatigue in Knee and Ankle Joint on Balance and Gait in Healthy Adults
}

\author{
Na-Kyung Lee', Young-Mi Kim¹, Kyoung Kim² \\ 'Department of Physical Therapy, Graduate School, Daegu University, Daegu; ${ }^{2}$ Department of Physical Therapy, College of Rehabilitation Science, \\ Daegu University, Daegu, Korea
}

Purpose: This study was to investigate the effects of unilateral muscle fatigue in knee and ankle joints on balance and gait in healthy adults.

Methods: Exercise inducing muscle fatigue in the knee joint consisted of concentric and eccentric contraction of dominant knee extensors in healthy adults by using the Leg Extension Rehap exercise machine (HUR, Finland). Exercise inducing muscle fatigue in the ankle joint was composed of voluntary contractions and forced contractions of the dominant plantar flexors in healthy adults. Exercises to induce muscle fatigue in the knee and ankle joints were performed until the subject complained of fatigue or pain, the occurrence of muscle fatigue was confirmed by electromyography. We measured static and dynamic balance using the Good Balance system and gait performance by RS-scan.

Results: Static and dynamic balance ability and spatial-temporal gait decreased significantly after muscle fatigue in knee and ankle joint.

Conclusion: These results show that unilateral muscle fatigue of the lower extremities affected postural control and gait. Therefore, therapists and sport trainers should minimize the risks of fall and injuries related to unilateral muscle fatigue.

Keywords: Unilateral muscle fatigue, Balance, Gait

\section{서 론}

운동으로부터 발생된 갑작스러운 근육의 힘 발휘 능력의 저하를 근 피로라고 정의한다.12이러한 근피로는 수의적으로 수축할 수 있는 최 대 힘의 감소량 혹은 최대하의 목표 힘으로 수축할 때 과제수행을 지 속적으로 유지할 수 없는 것으로 근피로의 정도를 나타낼 수 있다.3.4 근피로를 발생시키는 원인은 여러 가지 존재한다. 일반적으로 근육의 구심성 신경의 방전패턴 변화와 중앙처리 손상, 원심성 신경로의 손 상, 근 방추의 정보를 변경시키는 대사산물의 축적 등이 있다. 또한 근 피로는 근육을 수축하기 위한 모든 과정에서 발생되는 손상의 결과 라고 할 수 있으며, ${ }^{5}$ 외부 환경에 대한 반응시간, 관절의 위치 감각, 동 작의 협응력과 제어의 정확도와 같은 생역학적-신경근적 요인에 영 향을 미치며, 혈액 내 근 단백질 증가, 초기 지연성 근육통, 부종, 관절 의 가동범위 감소, 고유감각 기능과 신경근 제어기능의 감소를 수반 한다. ${ }^{67}$ 일상생활과 스포츠 활동에서 근피로는 특히 근골격계의 부
상으로 연결되며 상당한 시간적-물리적 손실을 야기한다.89

인간이 독립적인 생활을 하기 위하여 가장 필수적인 요소는 균형 과 보행능력이다.10,11 또한 균형과 보행능력에 하지의 기능은 매우 중 요하다. 그 중에서도 특히 무릎관절과 발목관절은 가장 중요한 요소 이다. 무릎관절은 하지에서 충격을 흡수하며, 체중부하를 위한 폄근 의 안정성을 조절해주며, 하지의 전진 동안 빠르게 굴곡하여 길이를 적절하게 조절해준다. 발목관절의 역할은 보행을 하는 동안 에너지 효율을 증가시켜 보행을 좀 더 편하게 할 수 있도록 한다. 또한 체간을 이동하는 데 필요한 추진력과 진행방향을 제공해주며, 물리적 충격 을 흡수하고 체 중심이동에 반응하여 균형을 유지할 뿐만 아니라 발 자체의 안정성에도 큰 역할을 수행한다.

최근 일상생활에서 편측의 과도한 작업부하와 반복 동작, 근력을 제대로 발휘할 수 없는 자세 등에서 오는 근피로도 증가에 따른 손상 이 최근 자주 발생하고 있는 추세이다. ${ }^{2}$ 또한 여가 생활의 증가와 더 불어 스포츠에 의한 손상의 비율도 증가하고 있는데 어느 한 쪽의 운 
동신경을 잦은 빈도로 자극하거나 심한 근수축 운동을 지속하게 되 면 근력 감소 등 피로현상이 발생되어 무릎관절과 발목관절에 여러 가지 문제가 발생하게 된다. 이러한 피로에 의한 손상은 일상생활 활 동이나 운동을 수행하는 데 있어서 손상을 일으키는 잠재적인 요인 이 된다. ${ }^{13.14}$ 또한 편측 근피로에 대한 연구는 정형계 환자나 신경계 환 자들에게 유발되는 비 손상측을 과도하게 사용함으로 유발되는 근 피로 위험성을 예측할 수 있는 자료로 사용될수 있다.

하지 근피로에 관한 연구들의 대부분은 양측 하지의 근피로가 자 세조절에 어떠한 영향을 주는지에 초점이 맞추어져 있다. 또한 편측 하지의 근피로가 균형 및 보행의 시공간적 변인에 어떠한 영향을 주 는지에 대한 연구는 구체적으로 제시되지 않았다. 이에 본 연구는 건 강한 성인을 대상으로 편측 하지의 근피로가 균형 및 보행의 시공간 적 변인에 어떠한 영향을 주는지에 대한 세부적이고 정량화된 자료 를 제시하고자 한다.

\section{연구 방법}

\section{1. 연구대상}

본 연구는 대구에 거주하는 정상 성인 20 명을 대상으로 시행하였다. 본 연구 대상자들은 하지의 선천적인 기형이나 심각한 내-외과적 혹 은 신경학적인 질환이 없는 자로 연구의 목적 및 실험 방법에 대해 설 명을 충분히 한 후 실험에 참여하겠다는 동의를 얻고, 진행과 실험절 차를 알려주기 위해서 연구 보조원이 시범을 보인 후 시행하였다. 모 든 연구 대상자들은 균형 및 보행능력을 측정하기 전에 근피로와 운 동의 영향을 최소화하기 위해 측정 일주일 전부터 격한 운동을 하지 않도록 하였으며, 측정 전 10 분간 휴식을 취하도록 하였다. 근피로 전 과 후에 연구 대상자들의 정적-동적 균형능력과 보행능력을 측정하 였다. 모든 측정은 연구 대상자들의 기기사용에 대한 이해도가 다르 므로 측정에 대한 오차를 줄이기 위해 2 회의 평균값을 사용하였다.

\section{2. 실험방법 및 절차}

(1) 근피로 측정

연구 대상자들의 근피로 측정을 위해 MP150 (biopack system Inc., USA) 표면 무선 근전도 측정 장치를 사용하였다. 사용된 전극은 $\mathrm{Ag} / \mathrm{AgCl}$ 표 면전극을 사용하였고, 획득한 근전도는 $1,000 \mathrm{~Hz}$ 신호획득률(sampling rate)로 수집되며, 구간 필터링과 잡음제거를 위해 $60 \mathrm{~Hz}$ 노치 필터 (notch filter)를 사용하였다. 피부저항과 오류를 최소화하기 위하여 알코 올로 닦아 낸 후 완전히 마른 후에 활성전극과 접지전극을 부착하였다. 넙다리곧은근의 전극 부착 부위는 무릎뼈의 위쪽 끝에서 직상부로 약 9-17 cm 지점에 부착하였으며, 가자미근은 넙다리 안쪽 융기와 발목의 내측과 사이의 $2 / 3$ 지점에 부착하였다. 근피로가 발생한 것을 확인하기
위하여 측정된 근전도 신호를 주파수 분석 및 중앙주파수를 계산하여 근피로도를 수치화 한 뒤 포화되는 임계점을 확인하고 이 지점에서 근 피로가 발생한 것으로 하였다. 근육의 피로가 쌓이게 되면 중앙주파수 가 증가하는 상태를 보이다가 일정지점 이후부터는 포화상태를 이루 게 되어 더 이상 증가하지 않고 평형에 가까운 상태를 보이게 된다. 본 논문에서는 이 지점을 근육의 임계점으로 정하였다.

\section{(2) 근피로 유발방법}

근피로 유발방법은 무릎과 발목관절에 집중한 근피로 유발 운동으 로 준비운동 5 분을 포함하여 시행하였다. 근피로는 자세조절과 보행 능력에 큰 영향을 미치는 무릎관절 폄근(넙다리곧은근), 발목관절 발바닥쪽굽힘근(가자미근)에 근피로 운동을 실시하였으며, 근피로 유발 순서는 무작위로 실시하였으며, 한 관절의 근피로 적용 후 일주 일 지난 뒤 다음 관절의 근피로 적용을 실시하였다. 무릎관절 근피로 유발운동은 하지 신전 운동훈련기(leg extensor rehab machine, HUR, Finland)를 이용하여 건강한 성인의 우세측 무릎 폄근에 최대 수의적 수축(maximum voluntary contraction)을 시행하였다. 대상자가 피곤 하거나 통증을 느낄 때까지 실시하며 근전도를 이용하여 근피로 발 생을 확인하였다.15,16

발목관절 근피로 유발운동은 Gefen 등17의 연구에서 적용한 피로 검사(fatigue test) 방법을 사용하였다. 이 방법은 수의수축(voluntary contraction)과 부하수축(forced contraction)으로 구성되어 있으며, 수 의수축은 양 발이 닿지 않는 높이의 의자에 앉은 상태에서 건강한 성 인이 우세측 발의 발등쪽굽힘과 발바닥쪽굽힘을 40 회 반복하는 것 으로 시행하였다. 수의 수축을 시행한 후 부하수축을 이어서 수행하 도록 하였다. 연구대상자들은 우세측 다리로 한발 서기 자세에서 발 목관절을 발바닥쪽굽힘하여 최대한 발뒤꿈치를 높이 들어 올리도록 하였으며, 1초 동안 유지한 후 다시 발뒤꿈치를 내리는 동작을 수행 하였다. 이때 신체가 균형을 유지할 수 있도록 연구대상자들의 우세 측 손의 접촉은 허용되었다. 무릎관절의 근피로와 동일하게 대상자 가 피곤하거나 통증을 느낄 때까지 실시하며 근전도를 이용하여 근 피로 발생을 확인하였다.

\section{3. 측정도구 및 방법}

본 연구에서 하지 근피로 적용 후 연구 대상자의 동적, 정적 균형조절 능력을 알아보기 위해 균형측정장치(good balance system ver. 3.06, METITER Inc., USA)를 사용하였다. 이 기계는 기울임이 불가능한 발 판이 있으며 발 뒤꿈치에 수직으로 작용하는 힘을 측정할 수 있다. 정 적 균형 능력은 정적인 자세에서 두 발을 모으고 압력 중심을 측정하 는 방법이고, 동적 균형 능력은 컴퓨터 화면 경로를 따라 압력 중심 을 정확한 순서로 도달하게 하여 측정하였다. 연구 대상자들의 보행 
능력을 측정하기 위하여 $2 \mathrm{~m}$ 길이의 Plate 형태인 보행능력 측정기구 (RS-scan system, RS scan Ltd., Germany)를 사용하여, 보행의 시공간적 요소를 분석하였다. 보행 시 연구 대상자는 최대한 편안한 자세로 자 신의 평소 걸음걸이 자세로 걷도록 실시하였다.

\section{4. 자료분석}

대상자들의 일반적인 특성을 알아보기 위하여 기술통계방법을 사 용하였다. 연구대상자의 근피로 전과 후의 유의성 검정은 대응표본 $\mathrm{t}$ 검정(paired t-test)을 사용하였다. 유의수준은 $\alpha=0.05$ 로 하였다. 본 연 구에서의 모든 자료는 평균 및 표준 오차로 제시하였고, 모든 자료는 SPSS version 18.0 버전을 사용하여 분석하였다.

\section{결 과}

\section{1. 연구 대상자의 특성}

대상자의 일반적 특징은 총 20 명 (남자 14 명, 여자 6명)이며, 평균연령
은 53.9세, 평균 신장은 $165.2 \mathrm{~cm}$, 평균 몸무게는 $69.5 \mathrm{~kg}$ 이다.

\section{2. 무릎관절의 근피로}

눈을 뜬 상태의 전-후 동요속도(EO)는 무릎관절 근피로 전, 후 유의한 차이를 보이지 않았으며(p>0.05) (Table 1), 좌-우 동요속도(EO)는 무릎 관절 근피로 전, 후 유의한 차이를 보였다 $(\mathrm{p}<0.05)$ (Table 1). 눈을 감은 상태의 전-후 동요속도(EC)는 무릎관절 근피로 전, 후 유의한 차이를 보이지 않았으며(p>0.05) (Table 1), 좌-우 동요속도(EO)는 무릎관절 근 피로 전, 후 유의한 차이를 보였고 $(\mathrm{p}<0.05$ ) (Table 1 ), 총 이동거리는 무 릎관절 근피로 전, 후 유의한 차이를 보였다 $(\mathrm{p}<0.05)$ (Table 1$).$

보장은 무릎관절 근피로 전, 후 유의한 차이를 보였으며 $(\mathrm{p}<0.05)$ (Table 1), 활보장은 무릎관절 근피로 전, 후 유의한 차이를 보이지 않았 고( $\mathrm{p}>0.05$ ) (Table 1), 보장시간은 무릎관절 근피로 전, 후 유의한 차이 를 보이지 않았다(p>0.05) (Table 1). 보행속도는 무릎관절 근피로 전, 후 유의한 차이를 보이지 않았으며(p>0.05) (Table 1), 지지기저면은 무 릎관절 근피로 전, 후 유의한 차이를 보이지 않았다 $(\mathrm{p}>0.05)$ (Table 1$)$.

Table 1. The changes of balance and gait before and after knee muscle fatigue

\begin{tabular}{|c|c|c|c|c|c|c|}
\hline & & & Pre & Post & $\mathrm{t}$ & $p$ \\
\hline \multirow[t]{10}{*}{ Knee fatigue } & \multirow[t]{5}{*}{ Balance } & A-P sway velocity (EO) (mm/s) & $5.33 \pm 1.16$ & $5.53 \pm 1.15$ & -1.23 & 0.23 \\
\hline & & M-L sway velocity $(E O)(\mathrm{mm} / \mathrm{s})$ & $6.49 \pm 1.87$ & $7.37 \pm 1.92$ & -2.41 & $0.03^{*}$ \\
\hline & & A-P sway velocity $(E C)(\mathrm{mm} / \mathrm{s})$ & $8.24 \pm 1.76$ & $8.73 \pm 1.71$ & -1.77 & 0.09 \\
\hline & & M-L sway velocity $(E C)(\mathrm{mm} / \mathrm{s})$ & $10.58 \pm 2.07$ & $11.77 \pm 2.42$ & -2.28 & $0.03^{*}$ \\
\hline & & Total distance (mm) & $1,315.35 \pm 308.48$ & $1,442.98 \pm 280.18$ & -2.42 & $0.03^{*}$ \\
\hline & \multirow[t]{5}{*}{ Gait } & Step legth (cm) & $46.33 \pm 3.63$ & $45.48 \pm 3.75$ & 3.43 & $0.00^{*}$ \\
\hline & & Stride length $(\mathrm{cm})$ & $91.56 \pm 6.26$ & $90.98 \pm 6.16$ & 2.06 & 0.06 \\
\hline & & Step time (sec) & $0.65 \pm 0.06$ & $0.65 \pm 0.05$ & -1.28 & 0.22 \\
\hline & & Gait velocity (m/s) & $0.95 \pm 0.13$ & $0.92 \pm 0.12$ & -1.28 & 0.15 \\
\hline & & $\mathrm{H}-\mathrm{H}$ BOS (\%) & $11.15 \pm 0.59$ & $11.31 \pm 0.60$ & -0.80 & 0.43 \\
\hline
\end{tabular}

All values are shown in mean \pm standard deviation.

EO: eyes open, EC: eyes closed.

*significant difference between pre- and post-test $(p<0.05)$.

Table 2. The changes of balance and gait before and after ankle muscle fatigue

\begin{tabular}{|c|c|c|c|c|c|c|}
\hline & & & Pre & Post & $\mathrm{t}$ & $p$ \\
\hline \multirow[t]{10}{*}{ Ankle fatigue } & Balance & A-P sway velocity $(E O)(\mathrm{mm} / \mathrm{s})$ & $5.32 \pm 1.15$ & $5.81 \pm 1.11$ & -1.94 & 0.07 \\
\hline & & M-L sway velocity (EO) (mm/s) & $6.49 \pm 1.87$ & $7.15 \pm 1.81$ & -5.18 & $0.00^{*}$ \\
\hline & & A-P sway velocity $(E C)(\mathrm{mm} / \mathrm{s})$ & $8.24 \pm 1.76$ & $9.83 \pm 3.01$ & -3.21 & 0.01 \\
\hline & & M-L sway velocity $(E C)(\mathrm{mm} / \mathrm{s})$ & $10.58 \pm 2.07$ & $12.31 \pm 2.80$ & -2.70 & 0.01 \\
\hline & & Total distance (mm) & $1,315.35 \pm 308.48$ & $1,383.23 \pm 320.07$ & -4.27 & $0.00^{*}$ \\
\hline & Gait & Step length (cm) & $46.33 \pm 3.63$ & $45.73 \pm 3.82$ & 2.26 & 0.04 \\
\hline & & Stride length $(\mathrm{cm})$ & $91.56 \pm 6.26$ & $91.01 \pm 6.38$ & 2.55 & $0.02^{*}$ \\
\hline & & Step time (sec) & $0.65 \pm 0.06$ & $0.66 \pm 0.05$ & -1.34 & 0.12 \\
\hline & & Gait velocity $(\mathrm{m} / \mathrm{s})$ & $0.95 \pm 0.13$ & $0.93 \pm 0.12$ & 1.41 & 0.17 \\
\hline & & $\mathrm{H}-\mathrm{H} B O S(\%)$ & $11.15 \pm 0.59$ & $11.74 \pm 0.70$ & -3.61 & $0.00^{*}$ \\
\hline
\end{tabular}

All values are shown in mean \pm standard deviation.

*significant difference between pre- and post-test $(p<0.05)$. 


\section{3. 발목관절의 근피로}

눈을 뜬 상태의 전-후 동요속도(EO)는 발목관절 근피로 전, 후 유의 한 차이를 보이지 않았으며(p>0.05) (Table 2), 좌-우 동요속도(EO)는 발목관절 근피로 전, 후 유의한 차이를 보였다 $(\mathrm{p}<0.05)$ (Table 2). 눈을 감은 상태의 전-후 동요속도(EC)는 발목관절 근피로 전, 후 유의한 차 이를 보였으며( $<<0.05$ ) (Table 2), 좌-우 동요속도(EO)는 발목관절 근 피로 전, 후 유의한 차이를 보였고( $\mathrm{p}<0.05$ ) (Table 2), 총 이동거리는 발 목관절 근피로 전, 후 유의한 차이를 보였다 $(\mathrm{p}<0.05)$ (Table 2).

보장은 발목관절 근피로 전 유의한 차이를 보였으며 $(\mathrm{p}<0.05)$ ( $\mathrm{Ta}-$ ble 2), 활보장은 발목관절 근피로 전, 후 유의한 차이를 보였고 $(\mathrm{p}<0.05)$ (Table 2), 보장시간은 발목관절 근피로 전, 후 유의한 차이를 보이지 않았다(p>0.05) (Table 2). 보행속도는 발목관절 근피로 전, 후 유의한 차이를 보이지 않았으며( $\mathrm{p}>0.05$ ) (Table 2), 지지기저면은 발목 관절 근피로 전, 후 유의한 차이를 보였다 $(\mathrm{p}<0.05)$ (Table 2).

\section{고 찰}

본 연구에서는 건강한 성인을 대상으로 무릎과 발목관절의 편측 근 피로가 균형 및 보행의 시공간적인 요인에 어떠한 영향을 주는지에 대해세부적이고 정량화된 자료를 제시하고자 한다.

본 연구결과 무릎관절 근피로 후 정적 균형능력인 눈을 뜬 상태와 눈을 감은 상태의 좌우 동요속도 그리고 동적 균형능력인 총 이동거 리에서 유의한 증가를 보였으며, 발목관절 근피로 후에는 눈을 뜬 상 태와 눈을 감은 상태의 좌우 동요속도, 눈을 감은 상태의 전후 동요속 도, 총 이동거리에서 유의한 증가를 보였다. $\operatorname{Lim}^{18}$ 은 양측 하지의 무 릎관절과 발목관절에 근피로를 유발시킨 후, 균형에 미치는 영향을 연구하였는데 그 결과, 무릎관절 폄근, 발목관절 발등쪽굽힘근, 발바 닥쪽굽힘근에 피로를 유발하였을 때 자세 동요가 크게 나타났다. 본 연구에서도 발목관절과 무릎관절 근피로 후 정적, 동적 균형능력이 감소되었으며, 더욱이 본 연구에서는 우세측의 하지의 근피로만 유 발하였기에 눈을 감았을 때와 뜨고 있는 상태의 좌-우 동요속도가 더욱 증가된 현상을 볼 수 있었다. 이는 근육의 반복적인 활동으로 장 시간 또는 과도한 활동으로 야기된 근피로는 최대 힘을 생산하는 데 제한을 주고 고유수용성 감각과 시각의 피드백 등의 입력에 손상을 주어 균형의 불안정성으로 자세중심 동요가 일어나 안정적인 자세를 유지하는 것이 어렵게 된 것으로 사료된다. ${ }^{19}$ 특히 발목관절의 근피로 는 무릎관절에 비해 좌-우 동요 속도뿐만 아니라 전-후 동요속도도 증가시키는 결과를 보였는데 이는 무릎관절과 비교하여 발목관절이 균형을 유지하는 데 더 많은 영향을 미치기 때문이다. ${ }^{18}$ 발목관절의 근육은 시상면에서 서 있는 자세나 한 발 서기 자세에서 일차적으로 균형을 유지하는 역할을 하는 반면, 무릎관절 근육은 균형을 유지함
에 있어 발목관절보다 그 비중이 작지만 과제의 난이도가 증가할 경 우에는 무릎관절 근육의 역할도 커지게 된다.

신체를 한 장소에서 다른 장소로 이동하기 위해 필수적인 것은 보 행능력이다. 일반적으로 정상적인 보행을 하기 위해서는 신체 중심을 완만하게 이동하기 위해 하지의 여러 관절이 잘 조화된 역학 운동이 일어나야 하며, 상지와 체간도 보행의 효율성을 증가시키기 위해 상 호 교대적으로 움직이는 것이 필요하다. ${ }^{10}$ 본 연구에서는 무릎관절 근 피로 후 보장에서 유의한 감소를 보였으며, 발목관절 근피로 후 보장, 활보장, 지지기저면에서 유의한 감소를 보였다. 무릎과 발목관절 근 피로 후 보행속도에서는 유의한 차이를 보이지 않았다. Barbieri 등15 은 젊은 여성들을 대상으로 하여 일어서기와 앉기를 반복하여 양하 지의 근피로를 유발한 뒤 보행에 미치는 영향을 살펴본 결과, 보장과 활보장의 길이의 감소가 나타나 본 연구 결과와 일치하였으나, 보행 속도는 감소하여 본 연구와 차이를 보였다. 이는 편측 근피로로 발생 한 기능적 소실을 정상 성인은 근피로를 적용하지 않은 무릎과 발목 근육을 이용하여 근피로를 적용한 하지의 기능을 보상할 능력이 있 기 때문으로 사료된다. 그러나 무릎관절의 근피로보다 발목관절의 근피로 후 보행의 요소들이 더욱 더 불안정한 결과를 보였는데 이는 무릎관절보다 발목관절의 근피로가 자세 안정성에 미치는 영향이 크기 때문으로 사료된다. Gimmon 등 20 은 발목관절의 근피로는 고유 수용성 감각의 감소를 일으키며 이로 인한 발목관절 질환과 사고가 많이 발생한다고 하였고, Spink 등른 하지 근육들 중 발목관절의 발 등쪽굽힘근의 노화 및 근력약화로 인하여 자세중심의 동요와 불안 정성이 일어난다고 하여 본 연구와 일치함을 보였다.

본 연구는 많은 수의 대상자를 포함시키지 못하였기 때문에 연구 결과를 일반화하기에는 제한이 따르며, 향후 더 많은 수를 보강하여 재분석한다면 더 의미 있는 결과를 도출할 것이다. 또한 추후에 삼차 원 동작분석을 이용한 전두면, 시상면, 수평면에서의 통합적인 보행 분석이 이루어진다면 좀 더 신뢰할 값을 도출할 수 있을 것이라 생각 된다. 근피로의 발생은 신경, 근육학적 측면의 기능소실로 자세 조절 능력의 감소를 증가시킬 뿐 아니라 낙상과 같은 보행적인 측면에서 위험성을 증가시킬 수 있다. 그러므로 인체 손상을 막고 균형, 보행 능 력을 증가시키기 위해서 다리의 각 근육의 근력과 지구력을 강화하 여 근피로 유발을 늦추고, 근피로가 발생한 경우에는 충분한 휴식을 통하여 이차적인 손상을 막는 것이 필요하다.

\section{참고문헌}

1. Allen DG, Westerblad H. Role of phosphate and calcium stores in muscle fatigue. J Physiol. 2001;536(3):657-65.

2. Miller RG, Kent-Braun JA, Sharma KR et al. Mechanisms of human muscle fatigue. Quantitating the contribution of metabolic factors and 
activation impairment. Adv Exp Med Biol. 1995;384:195-210.

3. Bellew JW, Fenter PC. Control of balance differs after knee or ankle fatigue in older women. Arch Phys Med Rehabil. 2006;87(11):1486-9.

4. Kanekar N, Santos MJ, Aruin AS. Anticipatory postural control following fatigue of postural and focal muscles. Clin Neurophysiol. 2008; 119(10):2304-13.

5. Gribble PA, Hertel J. Effect of hip and ankle muscle fatigue on unipedal postural control. J Electromyogr Kinesiol. 2004;14(6):641-6.

6. Christina KA, White SC, Gilchrist LA. Effect of localized muscle fatigue on vertical ground reaction forces and ankle joint motion during running. Hum Mov Sci. 2001;20(3):257-76.

7. Johnston RB, Howard ME, Cawley PW et al. Effect of lower extremity muscular fatigue on motor control performance. Med Sci Sports Exerc. 1998;30(12):1703-7.

8. Kellis E, Kouvelioti V. Agonist versus antagonist muscle fatigue effects on thigh muscle activity and vertical ground reaction during drop landing. J Electromyogr Kinesiol. 2009;19(1):55-64.

9. Urabe Y, Kobayashi R, Sumida $S$ et al. Electromyographic analysis of the knee during jump landing in male and female athletes. Knee. 2005; 12(2):129-34.

10. Kim G, Yoon NM. A Study on Kinetic Gait Analysis of the Normal Adult. J Kor Phys Ther. 2009;21(2):87-95.

11. Lee SY, Son GS, Jeon HJ et al. The Effects of Therapeutic Exercise on the Balance and Gait in Older Adults. J Kor Phys Ther. 2007;19(2):1-10.

12. Egerton T, Brauer SG, Cresswell AG. The immediate effect of physical activity on standing balance in healthy and balance-impaired older peo- ple. Australas J Ageing. 2009;28(2):93-6.

13. Wojcik LA, Nussbaum MA, Lin D et al. Age and gender moderate the effects of localized muscle fatigue on lower extremity joint torques used during quiet stance. Hum Mov Sci. 2011;30(3):574-83.

14. Reimer RC, Wikstrom EA. Functional fatigue of the hip and ankle musculature cause similar alterations in single leg stance postural control. J Sci Med Sport. 2010;13:161-6.

15. Barbieri FA, dos Santos PC, Vitorio R et al. Effect of muscle fatigue and physical activity level in motor control of the gait of young adults. Gait Posture. 2013;38(4):702-7.

16. Hatton AL, Menant JC, Lord SR et al. The effect of lower limb muscle fatigue on obstacle negotiation during walking in older adults. Gait Posture. 2013;37(4):506-10.

17. Gefen A, Megido-Ravid M, Itzchak Y et al. Analysis of muscular fatigue and foot stability during high-heeled gait. Gait Posture. 2002;15(1):5663.

18. Lim GL. Effects of Muscle Fatigue in Lower Extremity on Balance during Standing in Healthy Adults. Daegu University. Dissertation of Master's Degree. 2013.

19. Nardone A, Tarantola J, Giordano A et al. Fatigue effects on body balance. Electroencephalogr Clin Neurophysiol. 1997;105(4):309-20.

20. Gimmon Y, Riemer R, O ddsson L et al. The effect of plantar flexor muscle fatigue on postural control. 2011;21(6):922-8.

21. Spink MJ, Fotoohabadi MR, Wee E et al. Foot and ankle strength, range of motion, posture, and deformity are associated with balance and functional ability in older adults. Arch Phys Med Rehabil. 2011;92:68-75. 